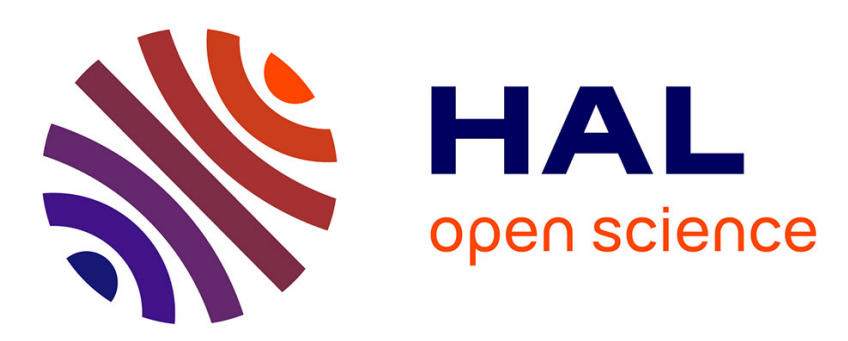

\title{
Influence of carbon nanotubes on fire behaviour and aerosol emitted during combustion of thermoplastics
}

C. Chivas-Joly, C. Motzkus, E. Guillaume, S. Ducourtieux, L. Saragoza, D. Lesenechal, José-Marie Lopez-Cuesta, C. Longuet, Rodolphe Sonnier, Benoît Minisini

\section{To cite this version:}

C. Chivas-Joly, C. Motzkus, E. Guillaume, S. Ducourtieux, L. Saragoza, et al.. Influence of carbon nanotubes on fire behaviour and aerosol emitted during combustion of thermoplastics. FIRE AND MATERIALS, 2014, 38 (1), pp.46-62. 10.1002/fam.2161 . hal-02914235

\section{HAL Id: hal-02914235 \\ https://hal.science/hal-02914235}

Submitted on 25 May 2021

HAL is a multi-disciplinary open access archive for the deposit and dissemination of scientific research documents, whether they are published or not. The documents may come from teaching and research institutions in France or abroad, or from public or private research centers.
L'archive ouverte pluridisciplinaire HAL, est destinée au dépôt et à la diffusion de documents scientifiques de niveau recherche, publiés ou non, émanant des établissements d'enseignement et de recherche français ou étrangers, des laboratoires publics ou privés. 


\title{
Influence of carbon nanotubes on fire behaviour and aerosol emitted during combustion of thermoplastics
}

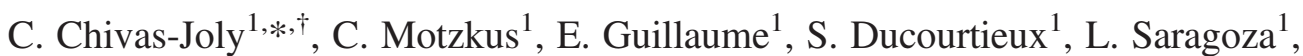 \\ D. Lesenechal ${ }^{1}$, J-M. Lopez-Cuesta ${ }^{2}$, C. Longuet $^{2}$, R. Sonnier ${ }^{2}$ and B. Minisini ${ }^{3}$ \\ ${ }^{1}$ LNE 29 Avenue Roger Hennequin 78197 Trappes Cedex, France \\ ${ }^{2}$ CMGD - Ecole des Mines d'Alès 6 Avenue de Clavières, 30319 Alès Cedex, France \\ ${ }^{3}$ ISMANS 44 Avenue F. A. Bartholdi, 72000 Le Mans, France
}

\begin{abstract}
Carbon nanotube-based poly(methyl methacrylate) and polyamide- 6 nanocomposites have been investigated using various techniques within the framework of the NANOFEU project. Scanning transmission electron microscopy was used to characterize morphologies of composites, while fire properties were studied using cone calorimeter and pyrolysis combustion flow microcalorimeter. The study focused particularly on composition and microstructure of gaseous and aerosol products. Morphology of ultrafine particles released from the combustion of nanocomposites was studied using cascade impactor and atomic force microscopy. Fire behaviour has been interpreted in relation with the degradation mechanisms specifically induced by the presence of carbon nanotubes.
\end{abstract}

KEY WORDS: nanofillers; cascade impactor; fire behaviour; aerosol; size distribution; carbon nanotube

\section{INTRODUCTION}

Since the beginning of the 1990s, the number of inventoried natural or synthesized nanoparticles did not cease to increase. This growing interest is because materials at the nanometric scale are known to exhibit different physical, chemical, electrical, and optical properties significantly compared with the properties of their equivalents at macroscopic scale. From an industrial point of view, new opportunities have emerged to develop innovative products containing nanoparticles in the fields of health, energy, information, and transport areas. In parallel, different issues related to the safety of nanosciences and nanotechnologies have been addressed [1-8]. However, they are often inconclusive and difficult to be compared because of the lack of scientific data and measurement traceability [9]. Whereas some research projects have focused mainly on the characterization of the nanoparticles themselves $[10,11]$, only to our knowledge, a US research project launched in 2010 by NIST $[12,13]$ and a French research project $[14,15]$ reported in this publication have provided results on the assessment of the risks of nanotechnologies in connection with the presence of nanoparticles in case of fire. In fact, many new materials contain nanoparticles such as polymer nanocomposites, in which nanoparticles (organomodified layered silicates, carbon nanotubes, nano-oxides or hydroxides, polyhedral oligomeric silsesquioxanes, etc.) are used as functional fillers, imparting high levels of functional properties: mechanical and barrier properties, fire retardancy, and so on. This category of materials can become a source of nanoparticles in

\footnotetext{
*Correspondence to: C. Chivas-Joly, LNE, 29 Avenue Roger Hennequin, 78197 Trappes Cedex - France.

${ }^{\dagger}$ E-mail: carine.chivas-joly@lne.fr
} 
accidental fire even if in some cases, nanoparticles are incorporated in the polymer, via flame retardant systems, in order to improve its fire retardancy. Within this context, the aim of NANOFEU French research programme [15], started in 2008, was to define and to implement a methodology aiming to the evaluation of the impact of nanofillers in polymers, in case of fire.

\section{BACKGROUND}

\subsection{The NANOFEU project}

The NANOFEU project focuses on the specific impact of nanofillers upon the smoke composition (gases and aerosols), by comparing polymers alone, polymers containing nanofillers, and polymers containing both nanofillers and flame retardants. Another issue addressed is the evaluation of the morphological modifications of ultrafine particles produced during the combustion of such materials for health hazard $[16,17]$. The consortium gathers experts in the following fields: fire sciences, physical and macromolecular chemistry, and numerical modelling. The project consortium is made up of five partners: Laboratoire national de métrologie et d'essais (LNE), Institut National de l'Environnement et des Risques (INERIS), École des mines d'Alès (EMA), Institut Supérieur des Matériaux et Mécaniques Avancées du Mans (ISMANS), and PlasticsEurope France (Professional Association of European Plastic Producers), which supports this academic group as an association of nanocomposites and polymer producers.

The methodology presented in this publication has been initially developed from the examination of the literature about nanoparticles and flame retardants in correlation with the various polymer matrices into which they have been incorporated. This led us to the selection of three different kinds of nanoparticles (silica, alumina, and carbon nanotubes) at different percentages and with also different surface treatments, as they can be considered as representative of components of various existing nanocomposites. It is important to note that the incorporation of montmorillonites is not considered despite their great applications in industries, because of the various products and applications resulting from the lamellar structure and the various functionalizations of the montmorillonites.

Hence, this paper focuses particularly on the influence of multiwall carbon nanotubes (MWCNT) incorporated in two polymeric matrices poly(methyl methacrylate) (PMMA) and polyamide-6 (PA-6) on their thermal stability and fire behaviour and on the characteristics of the corresponding aerosols released during combustion. A specific attention is paid on the morphology and nature of particles in aerosols and on the influence of the nature of nanoparticles on the degradation pathway of polymers.

\subsection{Case of poly(methyl methacrylate)}

Although the mechanism of PMMA degradation is also well known (it induces the depolymerization initiation with a first order termination, or depolymerization by the chains end, and chain random scissions), strong differences in rate constants and activation energy have been reported [18-20]. Kashiwagi et al. [21, 22] and Manring [23] have performed extensive studies of the PMMA thermal degradation, and two mechanisms are generally accepted for the degradation initiation under inert atmosphere. The first mechanism proposed by Kashiwagi et al. [19] proposes scissions within the main chain, whereas Manring [23] considers homolytic scissions of adjacent methoxycarbonyl groups. In the first case, an isobutyryl macroradical is formed (followed by $\beta$-scission-generating monomer); this first macroradical enables to estimate the extent of the $\beta$-scission in relation to the formation of methallyl-ended PMMA, $\mathrm{CO}, \mathrm{CO}_{2}$, and methoxymethyl radicals. In the second mechanism that favours the methoxycarbonyl group homolytic scission, the remaining polymer radicals can undergo $\beta$-scission, inducing an isobutyryl macroradical (which will effectively depolymerize) and a part of methallylic chain. It has been shown that the degradation products come from recombination and disproportionation reactions. Whatever the initiation step mechanism is, the product of degradation is almost exclusively the monomer, methyl methacrylate (>99\%) [24]. The different reaction paths are presented in Figure 1.

The thermo-oxidative degradation of PMMA has attracted much less attention in the past, although it would help to explain the fire behaviour more precisely. Brown et al. [25] studied the effect of oxygen on the PMMA chain scission subjected to thermal radiation, which conforms to the general 

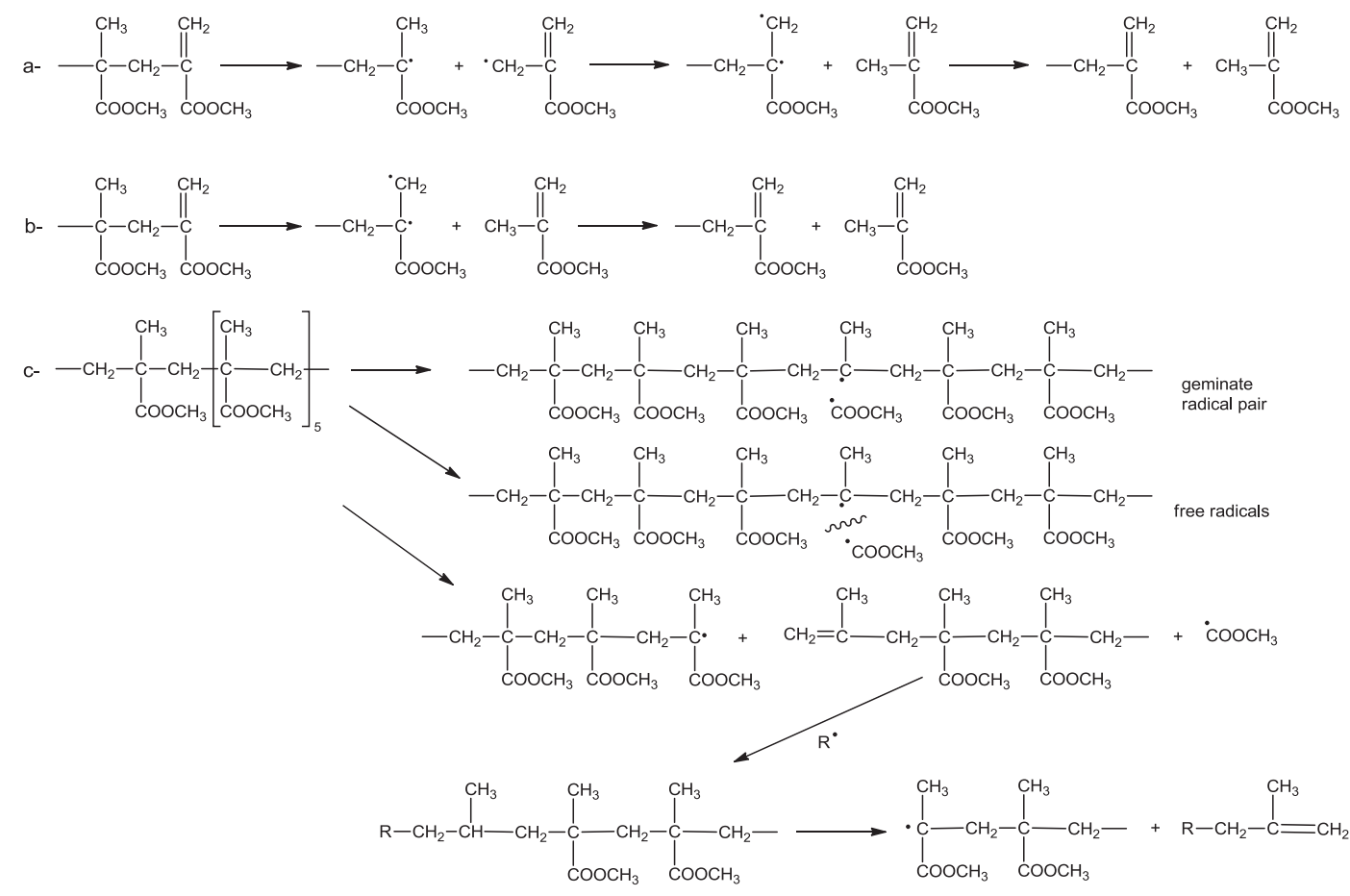

Figure 1. Thermal degradation of poly(methyl methacrylate). Reactions a- and b- describe the mechanisms defended by Kashiwagi (a- $\beta$-scission and b- ene reaction). Reactions c- illustrates the mechanisms proposed by Manring.

mechanistic scheme of polymer oxidation, according to Bolland [26-28]. These authors explained that oxygen would act on the unstable bonds such as unsaturated chain ends to form a more stable terminal hydroxyl function. Moreover, after degradation initiation, oxygen accelerates the depolymerization compared with the degradation in the inert atmosphere. The stabilizing effect of oxygen on the radicals from the chain end decomposition cannot be established for the PMMA, for which chain ends were stabilized or PMMA synthesized by anionic polymerization. Thus, one can conclude, according to Kashiwagi et al. [19], that oxygen promotes the random scission of the main chain, forming radicals that accelerate the complete depolymerization in relation to degradation without oxygen. Concerning the flammability properties of PMMA/SWCNT nanocomposites (single-wall carbon nanotubes at $0.5 \mathrm{wt} . \%$ ), Kashiwagi et al. [29, 30] have shown that the normalized mass loss rate peak is well correlated with respect to the quantified dispersion levels of nanotubes. These authors highlighted about $70 \%$ reduction in peak mass loss rate at the highest dispersion level used in this study. They proposed a mechanism based on the formation of many small 'islands'. Because the regions between the 'islands' were exposed to an undiminished external radiant flux, vigorous bubbling and bursting occurred preferentially between these 'islands'. It could explain why the mass loss rate and heat release rate of the samples with small SWCNT percentage are increased compared with samples containing higher nanotube contents. A similar process also occurred with PMMA/ SWCNT (0.5\%, poor dispersion) samples because of low melt viscosity (especially at high temperatures) even with the same amount of nanotubes. The authors have studied two formulations: the first is named PMMA/SWCNT (0.5 wt.\%) and the second, PMMA/SWCNT (0.5wt.\%, poor dispersion). The difference between these two formulations is the solvent content used to carry out the composite.

During the thermal degradation analysis, Kashiwagi et al. [30] have shown that the difference in morphology for PMMA/SWCNT nanocomposites had little influence. However, in a more recent study, Kashiwagi et al. [31] demonstrated that the addition of a small amount of SWCNT to PMMA slightly reduced its thermal stability approximately below $340^{\circ} \mathrm{C}$ but that it was slightly increased above this temperature. It was proposed that the physical integrity of the densely entangled carbon nanotubes layer was strong enough to remain intact during burning. 


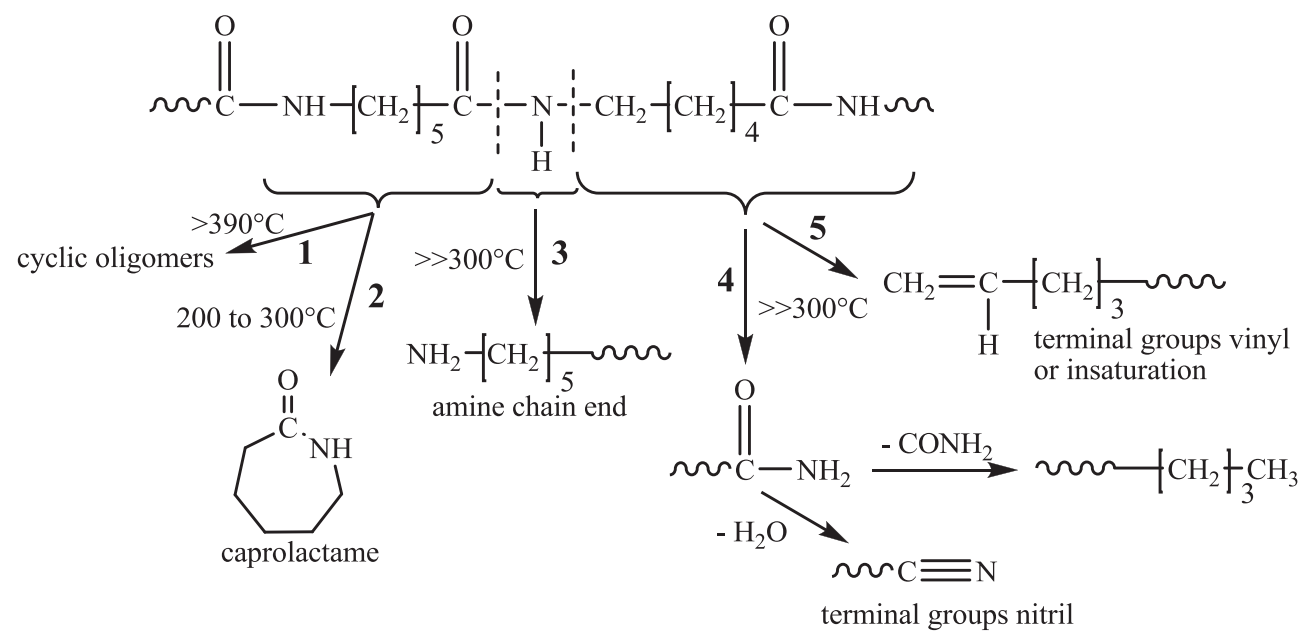

Figure 2. Thermal degradation of polyamide- 6 .

\subsection{Case of polyamide-6}

Polyamide- 6 has been widely studied either as virgin matrix or as nanocomposite [32]. Strauss and Wall [33] have shown that during thermal degradation of various PA-6 samples, 95\% of the released volatile products were heavy volatiles with chain fragments larger than five monomeric units. During the decomposition, different lighter compounds could be detected such as $\mathrm{CO}, \mathrm{CO}_{2}, \mathrm{CH}_{4}$, and $\mathrm{H}_{2}$. These authors suggested that the decomposition was initiated because of the weakness of the $\mathrm{CN}$ bond. It was assumed that the hydrolytic scission of the peptide bond $\mathrm{C}-(\mathrm{O})-\mathrm{NH}$ was the cause of the high concentration of $\mathrm{CO}_{2}$ emitted from the acidic groups decomposition produced by hydrolytic scission also. Kamerbeck et al. [34] have proposed two types of thermal decomposition reaction, the first taking place at temperatures below $300^{\circ} \mathrm{C}$ and the second beginning at temperatures above $300^{\circ} \mathrm{C}$ (Figure 2). Initially the amide chains end, nitrile, vinyl, isocyanate, and alkyl are generated. Dussel et al. [35] conducted the pyrolysis of PA-6 between $530^{\circ} \mathrm{C}$ and $800^{\circ} \mathrm{C}$ coupled with mass spectroscopy. They identified amines, amides, and nitrile fragments, characteristics of the thermal decomposition (Figure 2, routes 3, 4, and 5).

Ohtani et al. [36] and Michal et al. [37] found that the majority of volatile resulting from PA-6 was caprolactame and that some hydrocarbons and acrylonitrile were detected.

The influence of the carbon nanotubes addition in a PA-6 matrix has been well studied. Schartel et al. [38] have shown that there was almost no change in the decomposition except concerning the thermal stability of residues. Therefore, these authors concluded that nanotubes acted as inert fillers in PA-6, regarding the thermal decomposition. Because it is well known that the thermo-oxidation is an important factor causing ageing and degradation of PA-6 in air [39], the presence of MWCNT seems to delay the thermo-oxidation and therefore increase the thermal stability of composites in air. Even so, the effect of MWCNT on the thermal stability of composites was not easy to establish in inert atmosphere.

\section{EXPERIMENTAL APPROACH}

\subsection{Test methods used}

Table I summarizes the methods for measurements and test methods devoted to fire effluent at laboratory scale used for this publication. Standardized test protocols are mentioned when available.

\subsection{Aerosols characterization}

3.2.1. Aerosols distribution. The combustion model used was the cone calorimeter according to standard ISO 5660-1 [40]. The measurement of size distribution of the airborne particles in the range of $30 \mathrm{~nm}-10 \mu \mathrm{m}$ was made through a low-pressure cascade impactor (DLPI, Dekati Low 
Table I. Analytical methods used.

\begin{tabular}{|c|c|c|c|}
\hline \multicolumn{2}{|c|}{ Parameter and objectives } & \multirow{2}{*}{$\begin{array}{c}\text { Test apparatus } \\
\text { Cone calorimeter }\end{array}$} & \multirow{2}{*}{$\begin{array}{l}\text { Test method and test conditions } \\
\text { ISO } 5660-1 \text { [40] } \\
\text { Extraction airflow } 24 \mathrm{~L} \mathrm{~s}^{-1} \text {, irradiance } \\
50 \mathrm{~kW} \mathrm{~m}^{-2} \\
\text { Additional tests at various irradiance } \\
\text { levels for determination of CHF and TRP }\end{array}$} \\
\hline Fire behaviour & $\begin{array}{l}\text { Objectives are to } \\
\text { validate the fire } \\
\text { behaviour with } \\
\text { respect to the } \\
\text { literature }\end{array}$ & & \\
\hline & & $\begin{array}{l}\text { Microcalorimeter } \\
\quad(\mathrm{PCFC})\end{array}$ & $\begin{array}{l}\text { ASTM D } 7309-11 \text { [42] } \\
\text { Pyrolysis of a } 1-\mathrm{mg} \text { sample to } 750^{\circ} \mathrm{C} \text { at } \\
1 \mathrm{~K} \mathrm{~s}^{-1} \text { and combustion of gases at } \\
900^{\circ} \mathrm{C} \text { under air [43] }\end{array}$ \\
\hline \multirow[t]{2}{*}{$\begin{array}{l}\text { Morphology } \\
\text { and distribution } \\
\text { of aerosol } \\
\text { combustion }\end{array}$} & \multirow{2}{*}{$\begin{array}{l}\text { Objectives are to } \\
\text { identify chemical } \\
\text { and morphological } \\
\text { modifications induced } \\
\text { by nanofillers } \\
\text { on effluents }\end{array}$} & $\begin{array}{l}\text { Low-pressure } \\
\text { cascade } \\
\text { impactor } \\
\text { (DLPI) }\end{array}$ & ISO DIS 29904 [44] \\
\hline & & $\begin{array}{l}\text { Atomic force } \\
\text { microscopy }\end{array}$ & In air, tapping mode \\
\hline
\end{tabular}

PCFC, pyrolysis combustion flow calorimeter; CHF, critical heat flux; TRP, thermal response parameter.

Pressure Cascade Impactor, Tampere, Finland) followed by post-gravimetric analysis (Figure 3). The particles were collected on each stage by polycarbonate circular filter membranes.

Cone calorimeter main duct was modified in order to avoid the trapping of soot on the $90^{\circ}$ angle of the standardized exhaust duct and also to allow the sampling at a point where the flow of effluents can be considered as homogeneous. The incident irradiance was set at $50 \mathrm{~kW} \mathrm{~m}^{-2}$ with a ventilation rate standardized at $24 \mathrm{~L} \mathrm{~s}^{-1}$ according to the standard [40]. The sample size was reduced to $50 \mathrm{~mm} \times 50 \mathrm{~mm} \times 4 \mathrm{~mm}$ to limit particle saturation of equipments. The multistage aerosol sampling device separates particles by size, according to their inertial properties in a moving air stream. The inertia of a particle is a function of its diameter, shape, density, and velocity. The most common equivalent particle size is the aerodynamic particle diameter defined as the diameter of a spherical unit-density particle (equal to $1000 \mathrm{~kg} \mathrm{~m}^{-3}$ ) with the same gravitational settling velocity as the particle under consideration. The aerosol flow system transports the particles and collects the particles on a surface [41].

Each stage of the impactor is characterized by a 'cut-off size', also called $D_{50 \%}$. The 'cut-off size' corresponds to the aerodynamic diameter of particles trapped with an efficiency of $50 \%$ on a given stage. The aerodynamic diameter of the considering class is determined according to the cut-off diameter [44] such as $D_{\mathrm{a}}=\sqrt{D_{50 \% i} \cdot D_{50 \% i+1}}$.

Fire effluents (aerosol)

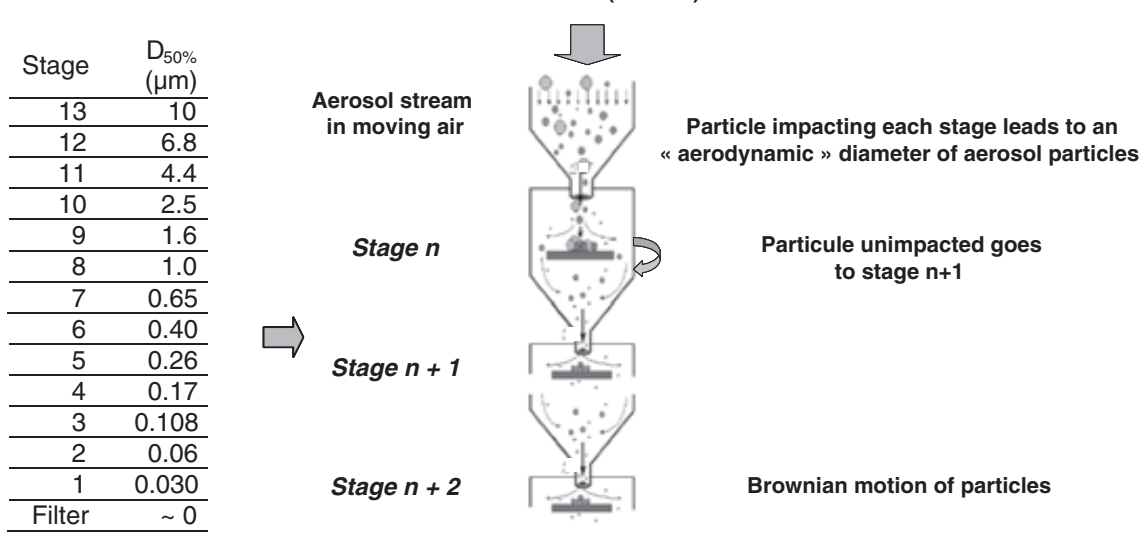

Figure 3. Multistage cascade impactor system with the cut-off diameter $D_{50 \%}$ of each stage for a sample flow rate equal to $10 \mathrm{~L} \mathrm{~min}^{-1}$. 
The expression for $D_{\mathrm{a}}$ should be explained, and probably, the ' $i$ ' and ' $i+1$ ' should also be subscripts. ' $i$ ' represent the stage of impaction, and $D_{\mathrm{a}}$ is the aerodynamic diameter of a channel.

The aerosol size distribution was obtained by measuring the mass of the particles collected at each stage of the impactor using a Mettler-Toledo (Greifensee, Switzerland) balance (10- $\mu$ g precision). A doubled weight gravimetric method was used: the gravimetric measurement of each filter before and after aerosol sampling was performed two times.

3.2.2. Aerosols morphology. The atomic force microscope (AFM) is one of the most used instruments in the industrial and academic world for the visualization of objects at nanometer scale. It draws its high resolving power from the interaction of the sample to be imaged with a tip whose apex has a curvature radius of about $10 \mathrm{~nm}$. By scanning the tip over the sample, the AFM is capable of reconstructing a three-dimensional image of the surface equally well in ambient air, under vacuum, or in liquid medium. Despite the many possibilities that it provides, its main use remains the observation of the topography of surfaces. The resolutions thus obtained are less than $1 \mathrm{~nm}$ vertically $(z)$ and horizontally $(x y)$ depend on the size and geometry of the tip (tip/sample convolution). AFM delivers therefore a lateral resolution less than SEM but compensates by delivering three-dimensional information where the SEM only delivers qualitative vertical information. Consequently, the two instruments are complementary.

To prepare suitable samples appropriate for AFM measurements, particles were collected using the low-pressure multistage cascade impactor described previously, where traditional polycarbonate circular collection membranes are replaced by optical microscope glass cover slips. After combustion of the formulation, the glass slip from the lower stage of the impactor (stage 1) was analysed. This slip corresponds to the stage where the collected particles are the smallest (aerodynamic diameter of $30 \mathrm{~nm}$ ) and the easiest to observe by AFM because they do not require a large range of displacement along the $z$-axis.

Prior to carrying out the AFM analysis, the cover slips were imaged using an optical microscope to locate the more suitable regions for AFM measurements. A set of images obtained at different magnifications is presented in Figure 4. Pictures show circular deposits with black dots at $\times 1$ magnification and black and grey discs at $\times 5$ and $\times 20$ magnifications. These deposits are composed of particles collected during the combustion. The granular texture of the deposit is more visible at $\times 100$ magnification. This typical deposit with regularly spaced discs is only due to the regularly spaced orifices that constitute a stage of the impactor and in which the particles are pulled through by the airflow. The airflow emerging from the orifice is deflected by the impaction surface and makes a sharp turn. Particles with sufficient inertia continue their straightforward movement and impact the collection surface. This leads to the creation of particle heaps in which the AFM scanning must be performed. On the centre of the heaps, the density of particles is too high for an AFM observation. Particles are aggregated, and their morphology cannot be easily determined. In addition, the heap height exceeds the AFM $z$ displacement range $(10 \mu \mathrm{m})$. AFM images were acquired on the edge of the deposit (see, for example, the cross-labelled A on the $\times 20$ magnification picture in Figure 4), where the concentration is sufficiently low to consider that no aggregation process occurs between particles during deposition on the surface and thus that the observed particles are representative of the ones present into the aerosol.

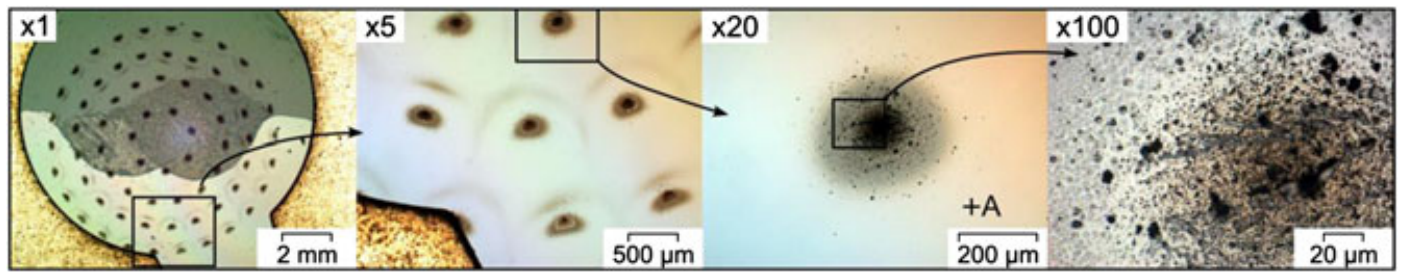

Figure 4. Example of microscopic photographs at different magnifications of the soot deposited on a cover slip after formulation combustion. The present slip was placed on the impactor stage number 1 where the $D_{50 \%}$ cut-off diameter is $30 \mathrm{~nm}$. 
After this optical characterization, the cover slips were imaged using an AFM with a scan range of $90 \mu \mathrm{m} \times 90 \mu \mathrm{m} \times 8 \mu \mathrm{m}$ and an accurate three-axis closed loop scanner (NanoMan VS from Digital Instruments, Santa Barbara, CA, USA, equipped with the hybrid XYZ scanner). This instrument was installed in an LNE clean room laboratory dedicated to dimensional metrology where humidity and temperature are, respectively, stabilized at $(50 \pm 5) \% \mathrm{HR}$ and $(20.00 \pm 0.05)^{\circ} \mathrm{C}$. To reduce vibrations that perturb AFM measurements, the instrument was protected with an acoustic/vibration isolation enclosure and equipped with a vibration isolation table. The system was also placed on a massive concrete block dissociated from the building to avoid mechanical vibration coming from the floor. These precautions associated with the performance of the instrument itself make the whole system very stable (very low drift) with low noise. OTESPA probes (Veeco Plainview, NY, USA) that possess a nominal radius of curvature of $7 \mathrm{~nm}$ and a nominal cantilever stiffness of $42 \mathrm{~N} \mathrm{~m}^{-1}$ were used to conduct AFM measurements in air using tapping mode. In this mode, the tip oscillates near its resonant frequency (about $300 \mathrm{kHz}$ ) with constant amplitude of about $30 \mathrm{~nm}$. When the tip reaches the surface, interaction forces modify the oscillation conditions of the resonator constituted by the tip and the cantilever. It leads to a modification of the oscillation amplitude. To keep this amplitude constant while the tip is scanning above the surface, a feedback loop controls the tip/ sample distance. The AFM topographical image was mapped by recording the tip/sample distance signal. A complementary signal of oscillation phase was also recorded during the scanning. This signal represents the phase shift between the excitation and the response of the tip. It was correlated to the energy dissipation of the resonator and linked to the properties (composition, adhesion, friction, viscoelasticity, etc.) of the materials encountered by the tip during the scanning. In general, phase image are better contrasted than topographical image, and in the case of aggregated particles, it allows clear separation each particles. The amplitude setpoint was set very high and near the free amplitude value to avoid strong interaction of the tip with particles that could provoke particle displacements. Thanks to the excellent stability of the system, a low scan speed $\left(2 \mu \mathrm{m} \mathrm{s}^{-1}\right)$ was applied to the scanner to obtain high quality and high-resolution images. Topographic and phase images were recorded without real-time filter.

\subsection{Materials studied}

3.3.1. Materials processing. Powder of PMMA (Altuglas BS9ELS) was kindly given by Arkema (Serquigny, France). A PA-6 masterbatch containing 20 wt.\% of MWCNT and the same PA-6 without nanofillers were kindly supplied by Arkema. These materials were processed to prepare six different compositions according to Table II. Thermogravimetric analysis (for PMMA-based and PA-6-based masterbatches) followed by SEM analysis (for PMMA-based masterbatch only) was performed to confirm the concentration in carbon nanotubes of the two masterbatches containing MWCNT.

Blends of polymers with carbon nanotubes were compounded using a twin screw extruder Clextral (Firminy, France), model BC 21 [L (length) $1200 \mathrm{~mm}$, L/D (length/diameter) 48, material flow $2.7 \mathrm{~kg} \mathrm{~h}^{-1}$, rotational speed of the screws $\left.200 \mathrm{rpm}\right]$ and pelletized, at $240^{\circ} \mathrm{C}$ for PMMA/MWCNT and at $250^{\circ} \mathrm{C}$ for PA-6/MWCNT. PMMA and commercial PMMA/MWCNT 5-wt.\% masterbatches were mechanically mixed prior to feeding in the extruder. The same protocol was used for PA-6 and commercial PA-6/MWCNT 20-wt.\% masterbatches.

Polymers and masterbatches were dried in vacuum at $80^{\circ} \mathrm{C}$ for $4 \mathrm{~h}$ before melt mixing. Specimens $(100 \mathrm{~mm} \times 100 \mathrm{~mm} \times 4 \mathrm{~mm})$ were moulded by injection using a 50-t KraussMaffei (München,

Table II. Samples studied: polymers alone and polymers containing nanofillers.

\begin{tabular}{llc}
\hline Sample no. & \multicolumn{1}{c}{ Composition of the sample } & Information on the nanofillers \\
\hline 0 & PMMA & None \\
9 & PMMA containing 0.2 wt.\% MWCNT & MWCNT \\
1 & PMMA containing $1 \mathrm{wt} \%$ MWCNT & None \\
12 & PA-6 & MWCNT \\
17 & PA-6 containing $0.2 \mathrm{wt} \%$ MWCNT & \\
13 & PA-6 containing $1 \mathrm{wt} \%$ MWCNT & \\
\hline
\end{tabular}

PMMA, poly(methyl methacrylate); MWCNT, multiwall carbon nanotubes; PA-6, polyamide-6. 
Germany) press at $260^{\circ} \mathrm{C}$ from the pellets, after air drying at $80^{\circ} \mathrm{C}$ for $4 \mathrm{~h}$. All the samples used for testing were cut from these specimens. All the nanocomposite formulations carried out contained 0.2 or 1 wt. $\%$ MWCNT.

3.3.2. Morphology of carbon nanotube-filled polymers. For such study, it is essential to validate the dispersion and the diffusion of carbon nanotubes in the samples. Three films cut using microtome have been used to perform scanning transmission electron microscopy (STEM) imaging of commercial and diluted masterbatches at $1 \mathrm{wt} . \%$ MWCNT. STEM was performed on a Hitachi S-4300 environmental scanning electron microscope Model Quanta 200 FEG (FEI Company, Hillsboro, OR, USA). As seen in Figure 5(a), the MWCNT dispersion in PMMA matrix is poor for the commercial masterbatch. After dilution (Figure 5(c)), aggregates from 200 to $500 \mathrm{~nm}$ are formed. MWCNT are better dispersed in PA-6 than in PMMA (Figure 5(b), (d)).

\section{RESULTS AND DISCUSSIONS}

\subsection{Fire behaviour}

Fire behaviour of pure polymers and nanocomposites was investigated using a cone calorimeter with an incident irradiance of $50 \mathrm{~kW} \mathrm{~m}^{-2}$ and a pyrolysis combustion flow calorimeter (PCFC) apparatus. Two specimens were tested in cone calorimeter, and three specimens were tested in PCFC.

Table III summarizes the main results measured with both methods for the following parameters: maximum heat release rate (pHRR), heat of combustion $\left(\Delta H_{\mathrm{C}}\right.$ ), and time to ignition (TTI) for cone

(a)

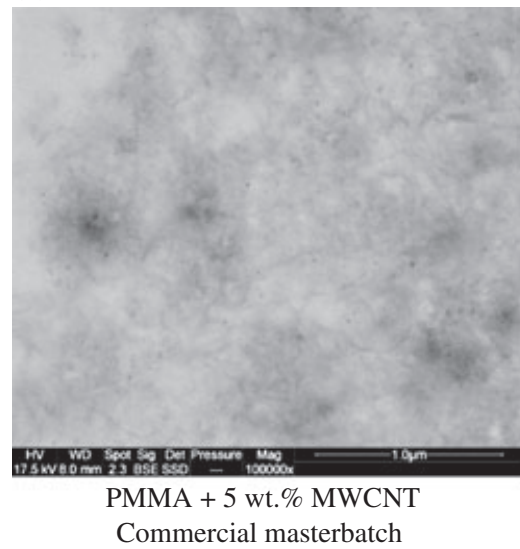

(c)

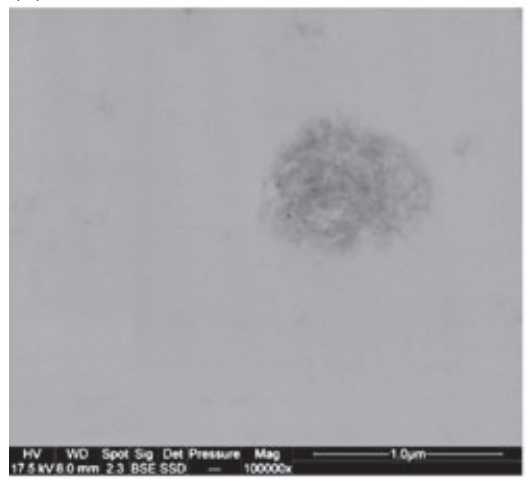

PMMA + 1 wt. $\%$ MWCNT (b)

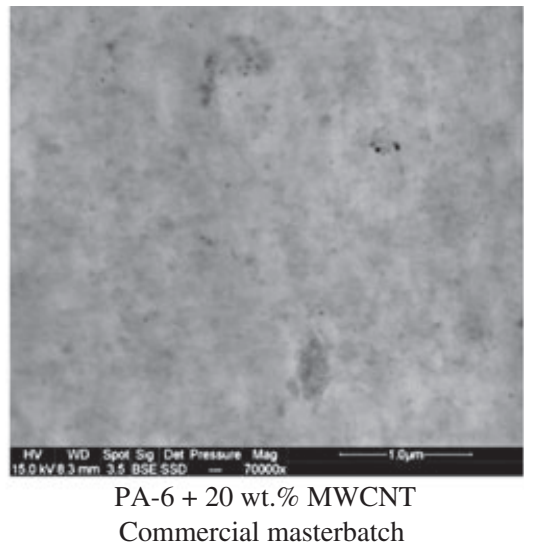

(d)

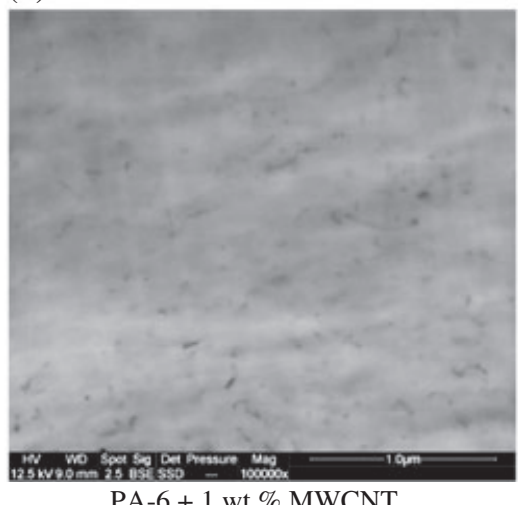

Figure 5. Compounds imaged by scanning transmission electron microscopy. 
Table III. Results for cone calorimeter at $50 \mathrm{~kW} \mathrm{~m}^{-2}$ and pyrolysis combustion flow calorimeter.

\begin{tabular}{|c|c|c|c|c|c|c|c|}
\hline \multirow{2}{*}{\multicolumn{2}{|c|}{ Material no./sample }} & \multicolumn{3}{|c|}{ Cone calorimeter } & \multicolumn{3}{|c|}{ PCFC } \\
\hline & & \multirow{2}{*}{$\begin{array}{c}\begin{array}{c}\mathrm{pHRR} \\
\left(\mathrm{kW} \mathrm{m}^{-2}\right)\end{array} \\
(1070 \pm 107)\end{array}$} & \multirow{2}{*}{$\begin{array}{c}\begin{array}{c}\Delta H_{\mathrm{C}} \\
\left(\mathrm{kJ} \mathrm{g}^{-1}\right)\end{array} \\
(25.2 \pm 2.5)\end{array}$} & \multirow{2}{*}{$\begin{array}{c}\text { TTI (s) } \\
(27 \pm 2)\end{array}$} & \multirow{2}{*}{$\begin{array}{c}\text { Peak temp. } \\
\left({ }^{\circ} \mathrm{C}\right)\end{array}$} & \multirow{2}{*}{$\frac{\begin{array}{c}\mathrm{HRC} \\
\left(\mathrm{J} \mathrm{g}^{-1} \mathrm{~K}^{-1}\right)\end{array}}{429}$} & \multirow{2}{*}{$\begin{array}{c}\begin{array}{c}\mathrm{THR}^{-1} \\
\left(\mathrm{~kJ} \mathrm{~g}^{-1}\right)\end{array} \\
23.4\end{array}$} \\
\hline 0 & PMMA & & & & & & \\
\hline 9 & $\begin{array}{l}\text { PMMA/MWCNT } \\
(0.2 \text { wt. } \%)\end{array}$ & $(1008 \pm 109)$ & $(24.6 \pm 2.5)$ & $(22 \pm 2)$ & 393 & 392 & 22.7 \\
\hline 1 & $\begin{array}{l}\text { PMMA/MWCNT } \\
\quad(1 \mathrm{wt} . \%)\end{array}$ & $(734 \pm 77)$ & $(25.0 \pm 2.5)$ & $(26 \pm 2)$ & 393 & 383 & 22.9 \\
\hline 12 & PA-6 & $(1306 \pm 131)$ & $(29.9 \pm 3.0)$ & $(50 \pm 9)$ & 467 & 618 & 28.3 \\
\hline 17 & $\begin{array}{l}\text { PA-6/MWCNT } \\
(0.2 \text { wt. } \%)\end{array}$ & $(1003 \pm 107)$ & $(29.6 \pm 3.1)$ & $(59 \pm 8)$ & 471 & 549 & 27.3 \\
\hline 13 & $\begin{array}{l}\text { PA-6/MWCNT } \\
\text { (1 wt.\%) }\end{array}$ & $(994 \pm 134)$ & $(30.6 \pm 3.1)$ & $(65 \pm 4)$ & 472 & 548 & 28.3 \\
\hline
\end{tabular}

PCFC, pyrolysis combustion flow calorimeter; PMMA, poly(methyl methacrylate); MWCNT, multiwall carbon nanotubes; PA-6, polyamide-6.

calorimeter; peak temperature, heat release capacity (HRC), and total heat release (THR) per unit of mass for PCFC. For cone calorimeter, curves of heat release rate are presented in Figure 6 for the average of two tests per composition. Uncertainties are presented in Table III, and Figure 7 included dispersion between tests and experimental uncertainty.

Additional determinations of effective critical heat flux (the minimum irradiance where ignition occurs in less than $30 \mathrm{~min}$ with cone calorimeter) and thermal response parameter (TRP - parameter linked to the thermal effusivity of the material between ambient and ignition temperatures) $[45,46]$ are highlighted in Table IV. Uncertainty on effective critical heat flux is estimated at $5 \%$.

a) PMMA and PMMA-based nanocomposites - mean curves

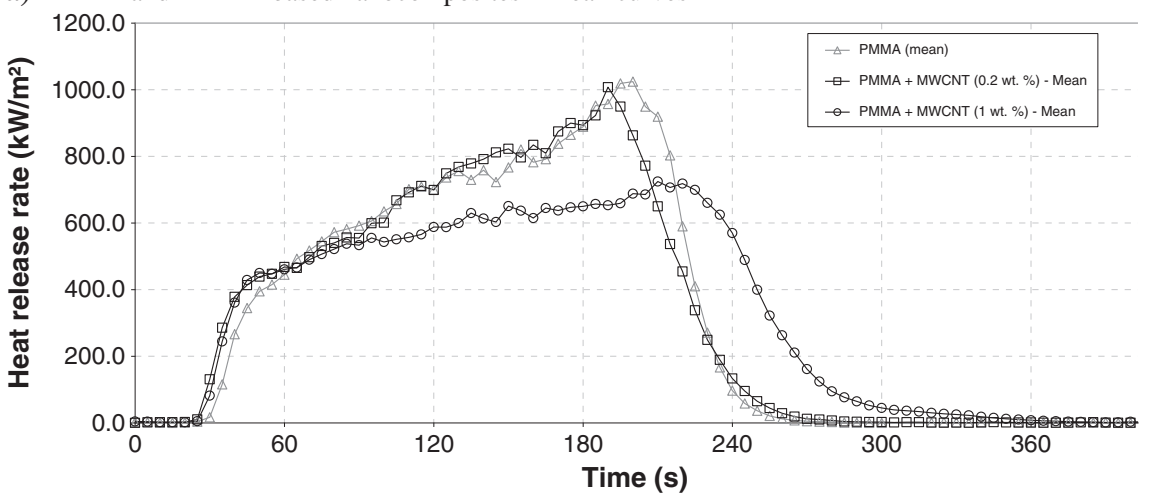

b) PA-6 and PA-6-based nanocomposites - mean curves

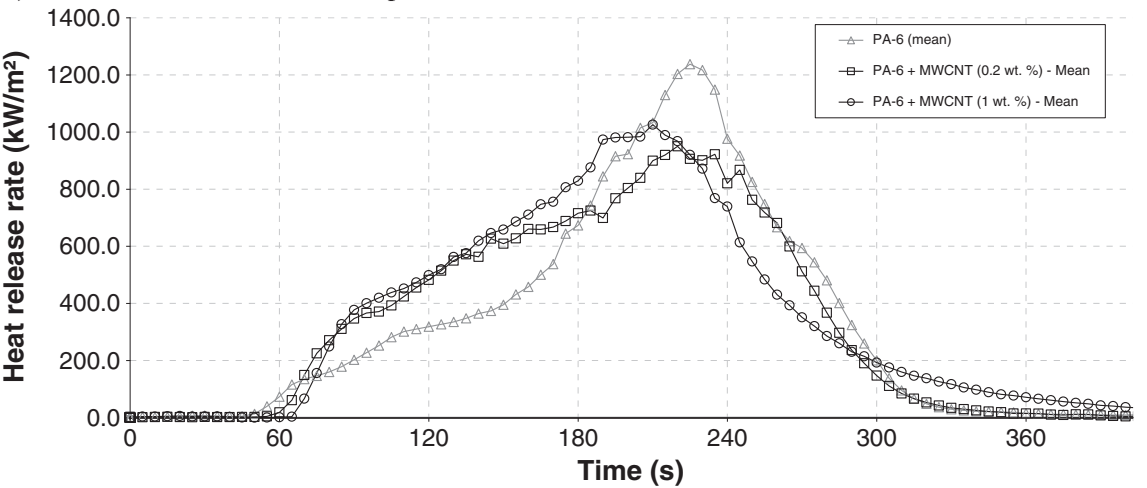

Figure 6. Cone calorimeter results on heat release rate. 
(a) Cone calorimeter

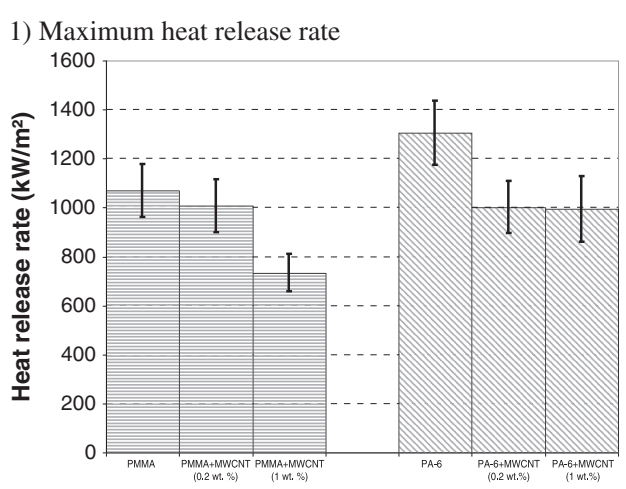

2) Heat of combustion

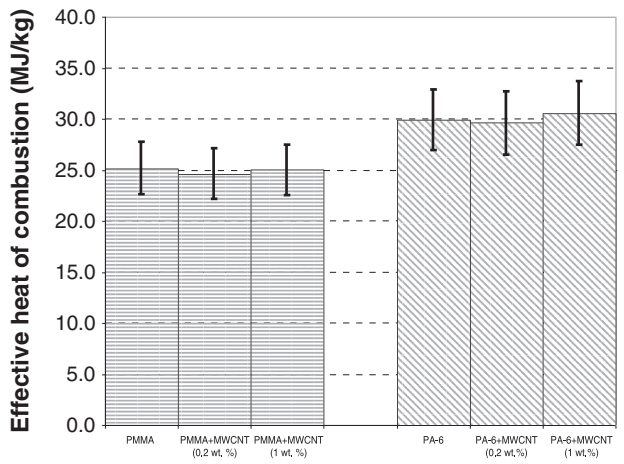

3) Time to ignition

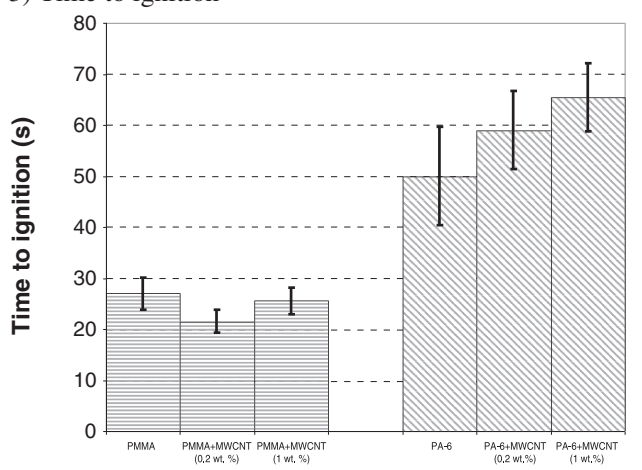

(b) PCFC

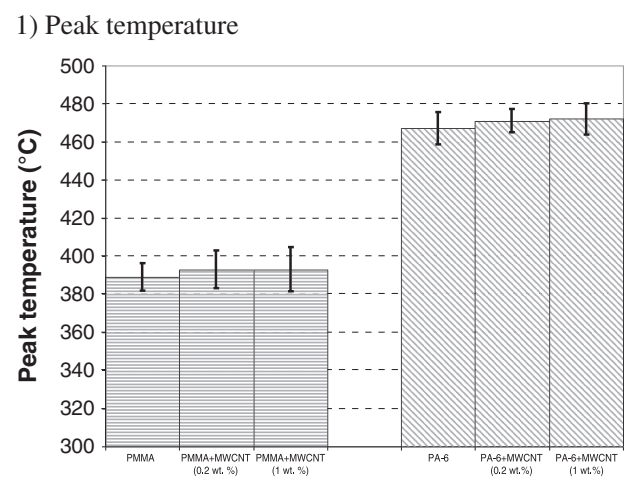

2) Heat Release Capacity

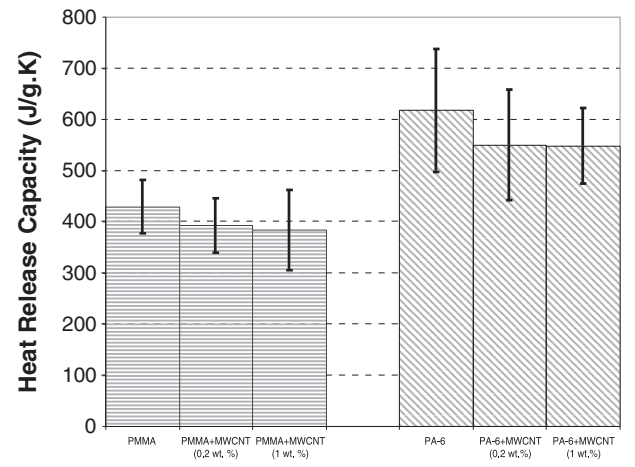

3) Total heat released

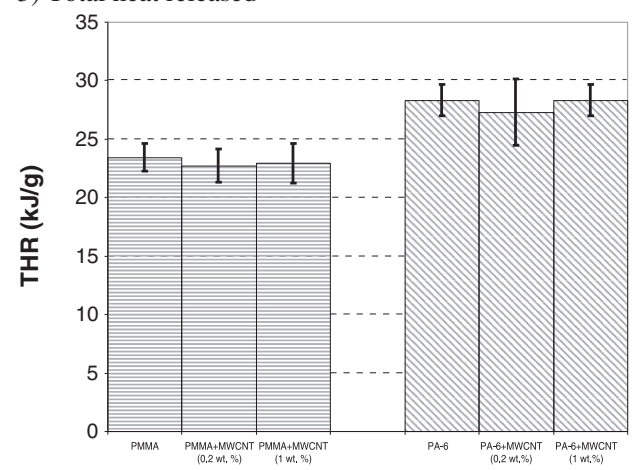

Figure 7. Plot of results for cone calorimeter and pyrolysis combustion flow calorimeter.

Table IV. Results for critical heat flux and thermal response parameter.

\begin{tabular}{llcc}
\hline Material no./sample & $\begin{array}{c}\text { Effective critical heat } \\
\text { flux }\left(\mathrm{kW} \mathrm{m}^{-2}\right)\end{array}$ & $\begin{array}{c}\text { Thermal response } \\
\text { parameter }\left(\mathrm{kJ} \mathrm{s}^{-0.5} \mathrm{~m}^{-2}\right)\end{array}$ \\
\hline 0 & PMMA & $10[47]$ & $\mathrm{ND}$ \\
9 & PMMA/MWCNT $(0.2 \mathrm{wt} \%)$ & $\mathrm{ND}$ & $\mathrm{ND}$ \\
1 & PMMA/MWCNT $(1 \mathrm{wt} \%)$ & 10 & $(294 \pm 19)$ \\
12 & PA-6 & 11 & $(421 \pm 29)$ \\
17 & PA-6/MWCNT $(0.2 \mathrm{wt} \%)$ & $\mathrm{ND}$ & $\mathrm{ND}$ \\
13 & PA-6/MWCNT $(1 \mathrm{wt} \%)$ & 12 & $(499 \pm 62)$ \\
\hline
\end{tabular}

ND, not determined; PMMA, poly(methyl methacrylate); MWCNT, multiwall carbon nanotubes; PA-6, polyamide-6. 
Uncertainty on thermal response parameter is determined as a function of the regression fit needed to calculate it.

The association of both techniques provides additional information about the mechanisms of degradation. In particular, the different scale for both tests (mg for PCFC, around $50 \mathrm{~g}$ for cone calorimeter) allows studying distinct phenomena influencing fire behaviour. Some effects such as physical barrier effect could have a great impact on fire behaviour in cone calorimeter test and not in PCFC.

With cone calorimeter, the effect of MWCNT depends on the matrix studied. For PA-6, the presence of MWCNT increases significantly ignition time and modifies thermal behaviour. This effect is not evident for PMMA. For both matrices, there is no evident change in effective heat of combustion with nanocomposites compared with virgin polymers. Nevertheless, the MWCNT addition influences strongly the heat release kinetics (Figure 7). A significant decrease in maximum heat release is observed for both polymers, especially for PA-6 nanocomposite where this effect is significant with only $0.2 \mathrm{wt}$.\% MWCNT. For PMMA, the effect is significant at $1 \mathrm{wt} . \%$ MWCNT.

Pyrolysis combustion flow calorimeter results are significantly different. The incorporation of MWCNT does not lead to an improvement in peak temperature or THR, whatever the matrix used. A trend, not significant regarding uncertainties, seems to show a reduction of HRC with the introduction of MWCNT for PA-6 nanocomposite. The strong differences observed between PCFC and cone calorimeter results can be ascribed to different physical behaviours because of the scale difference. In particular, in PCFC, the very low sample weight (approximately 1-2 mg) could not allow a barrier effect to be created in order to reduce the heat release rate. Moreover, changes in thermal transfer seen on TRP variation in cone calorimeter for PA-6 could not be seen in PCFC, where the sample is supposed to be thermally thin. Conversely, the influence of MWCNT on polymer degradation for cone calorimeter can be attributed to the creation of a protective layer, which is able to play a role of mass and heat diffusion barrier. Visual observations confirm this assertion. For example, pure PA-6 is melting and bubbling. When MWCNT are incorporated into PA-6, a fine but solid layer is formed at the top of the sample, which probably limits the release rate of gases to the flame. Thus, in these test conditions (samples of $100 \mathrm{~mm} \times 100 \mathrm{~mm} \times 4 \mathrm{~mm}$ ), a significant effect of MWCNT on fire combustion can be supposed.

\subsection{Aerosols characterization}

4.2.1. Aerosols distribution. The total mass and yield of aerosols produced are presented as average of three to five determinations in Table V and Figure 8. Uncertainty bars in Figure 8 represent both experimental standard deviation and measurement uncertainty, with a confidence of $95 \%$. Uncertainties are important, mainly because of experimental dispersions, and no conclusion on observed trends could be confirmed. Nevertheless, it seems that the presence of carbon nanotubes in PA-6 induces a more regular and repeatable combustion and leads to a better repeatability of tests. The presence of MWCNT seems to reduce the total aerosol yield for PA- 6 at $1 \mathrm{wt} . \%$, but the effect is not significant at $0.2 \mathrm{wt} . \%$. For PMMA-based nanocomposites, no significant variation is observed on total aerosol yield.

The quantity retained by the low-pressure cascade impactor (in wt. \%) for each particle size range is presented in Figure 9. A comparison of bar graphs obtained for all samples of PMMA and PA-6

Table V. Results for aerosol total mass and yield at $50 \mathrm{~kW} \mathrm{~m}^{-2}$.

\begin{tabular}{llccc}
\hline Material no./sample & Total mass (mg) & Yield $\left(\mathrm{mg} \mathrm{g}^{-1}\right)$ & $\begin{array}{c}\text { Relative uncertainty } \\
(\text { expanded, } k=2)(\%)\end{array}$ \\
\hline 0 & PMMA & 0.83 & 3.7 & 20 \\
9 & PMMA/MWCNT (0.2 wt.\%) & 1.09 & 4.6 & 30 \\
1 & PMMA/MWCNT (1 wt.\%) & 0.98 & 4.4 & 26 \\
12 & PA-6 & 1.22 & 5.7 & 83 \\
17 & PA-6/MWCNT (0.2 wt.\%) & 1.36 & 6.3 & 9 \\
13 & PA-6/MWCNT (1 wt.\%) & 0.93 & 3.9 & 9 \\
\hline
\end{tabular}

PMMA, poly(methyl methacrylate); MWCNT, multiwall carbon nanotubes; PA-6, polyamide-6. 


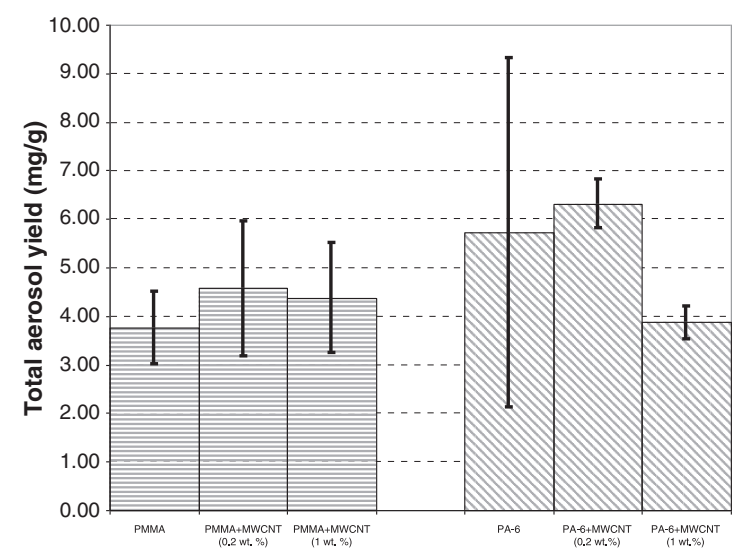

Figure 8. Plot of results for aerosol yields.

(a) PMMA

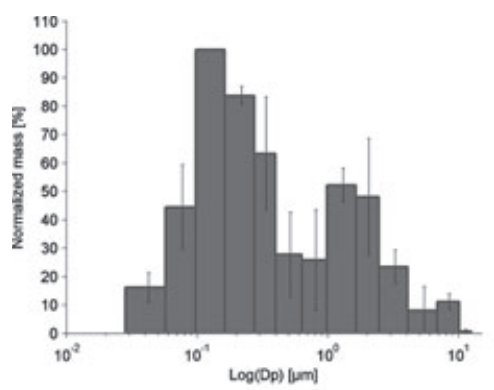

(b) PMMA + MWCNT (0.2 wt. \%)

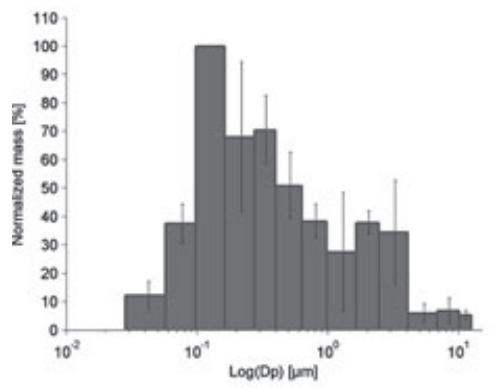

(c) PMMA + MWCNT (1 wt. \%)

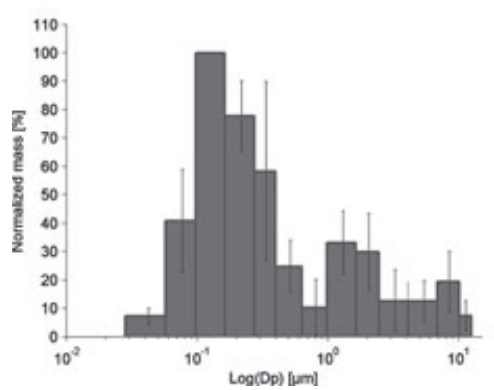

(d) PA-6

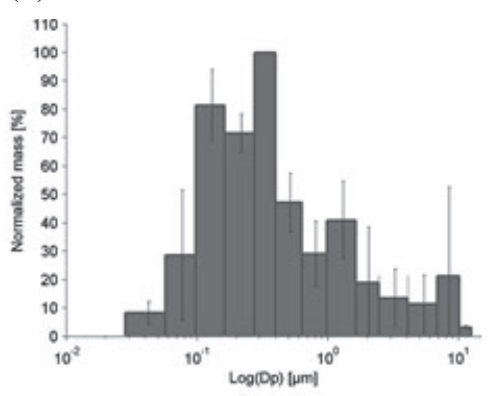

(e) PA-6+ MWCNT(0.2 wt. \%)

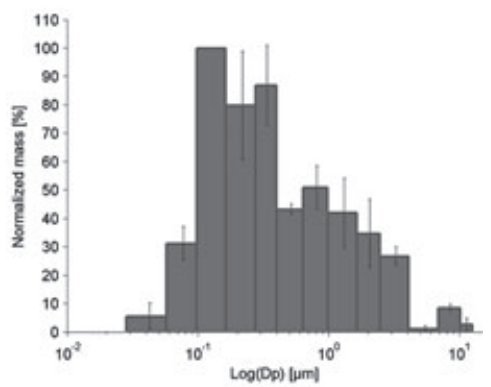

(f) PA-6+ MWCNT (1 wt. \%)

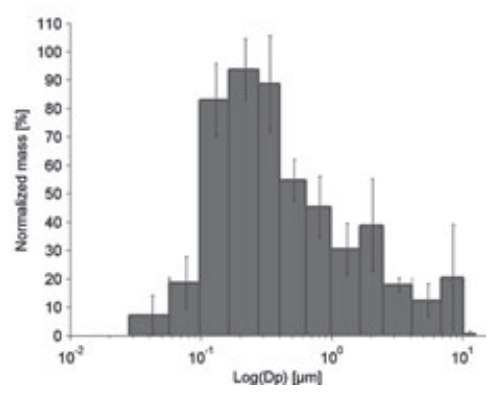

Figure 9. Particle mass distribution normalized versus $D_{\mathrm{p}}$ (where $D_{\mathrm{p}}$ is the aerodynamic diameter of the particle). 
studied shows the possible impact of nanofillers on soot size distribution and the influence of the nature of the matrix.

Figure 9 shows that the aerosols obtained in the case of the PMMA are polydispersed, even with and without carbon nanotubes. The modal diameters of size distributions are equal to the same $0.12 \mu \mathrm{m}$ class. In addition, PMMA without nanofillers seems to show a higher mass proportion of larger particles in the range $0.6-2.5 \mu \mathrm{m}$ than PMMA/MWCNT. Conversely, the size distribution for the PMMA/1 wt.\% MWCNT nanocomposite shows an increase in larger particles (larger than $4 \mu \mathrm{m}$, corresponding to the last three size classes of the impactor), compared with PMMA alone.

The PA-6 with or without nanofillers seems to show a mono-modal distribution with a mode diameter between 0.1 and $0.4 \mu \mathrm{m}$ with regard the uncertainties. The results presented in Figure 9 illustrate no significant difference in mass distribution between the PA-6 with and without MWCNT.

4.2.2. Morphology analysis using atomic force microscope. For each formulation, several combustions have been carried out, and many slides have been produced and imaged to test the repeatability of the observations (more than 20 images for each formulation). Figure 10 presents the

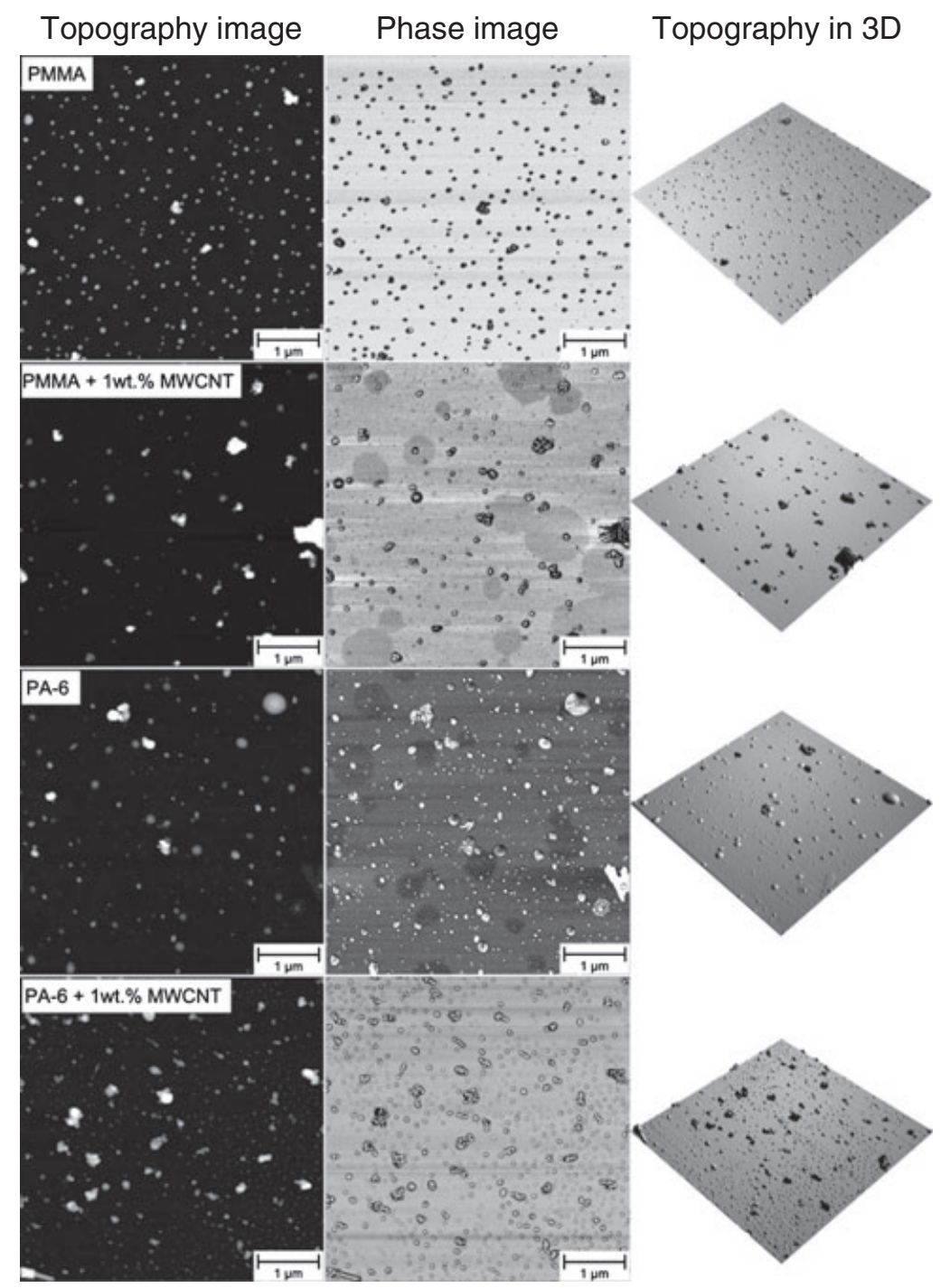

Figure 10. Atomic force microscope images of the particles collected on the first stage of the impactor (cut-off aerodynamic diameter, $30 \mathrm{~nm}$ ) for the poly(methyl methacrylate) (PMMA), PMMA/1 wt.\% multiwall carbon nanotubes (MWCNT), polyamide-6 (PA-6), and PA-6/1 wt.\% MWCNT formulations. 
most representative results obtained with AFM for the four formulations: PMMA, PMMA/MWCNT (1 wt.\%), PA-6, and PA-6/MWCNT (1 wt.\%). Images on the left give an overview of the collected particles' topography over a $5 \mu \mathrm{m} \times 5 \mu \mathrm{m}$ scan for each formulation. Images, on the centre, are more contrasted and represent phase images obtained simultaneously with topography images. Images on the right give a $3 \mathrm{D}$ representation of the topography.

On each image, particles and aggregates are clearly observable. In a general way, the aggregates produced by PMMA or PMMA/MWCNT are more compact than the one produced for the PA- 6 or PA-6/MWCNT. On the presented PMMA/MWCNT and PA-6 phase image, one can clearly see some stains not present on the topography image. Those stains are supposed to be attributed to a very thin deposit due to the evaporation of a collected liquid phase, which modifies the local stiffness of the surface and thus the phase signal. Those stains are not present on phase images for the PA-6/MWCNT formulation, neither for the PMMA formulation. These differences in the collected particles on the first stage are more visible in Figure 11, where magnification of the previous images is presented to observe in more detail the aggregates. For the PA-6/MWCNT formulation, nanotubes are clearly observable. This is not the case for the PMMA/MWCNT.
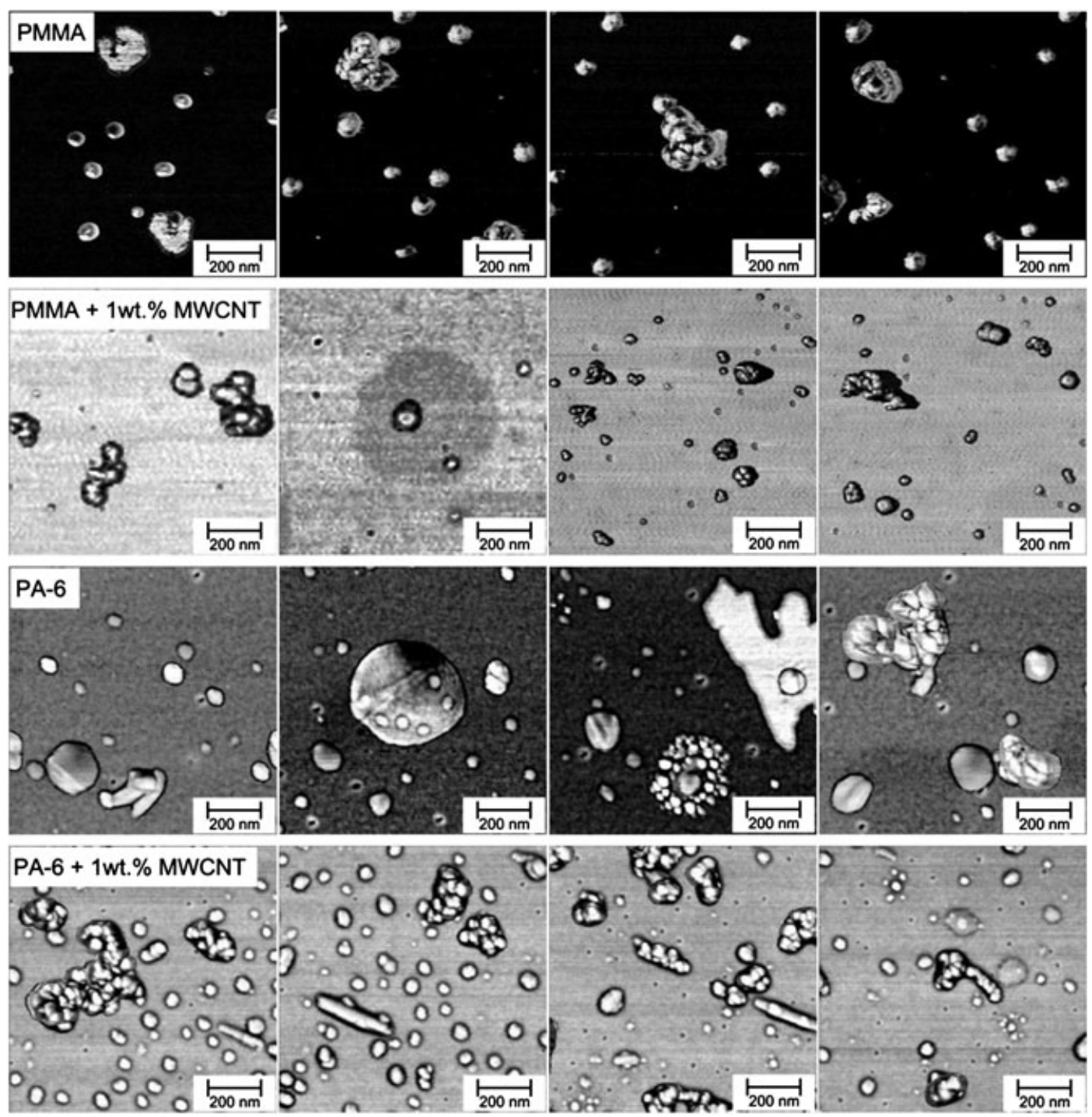

Figure 11. Atomic force microscope image zoom of particles and aggregates collected on the first stage of the impactor for poly(methyl methacrylate) (PMMA), PMMA/1 wt.\% multiwall carbon nanotubes (MWCNT), polyamide-6 (PA-6), and PA-6/1 wt.\% MWCNT formulations. 
One hypothesis is proposed to explain the possible presence of carbon nanotubes: as carbon nanotubes incorporated in matrices are issued from different masterbatches, we suppose that their size distributions are different. Maybe MWCNT introduced in PMMA are larger than those introduced in PA-6. In the case of the PMMA + MWCNT formulation, we suppose that the carbon nanotubes have an aerodynamic diameter too large to impact the first stage of the impactor, where the cut-off aerodynamic diameter is only $30 \mathrm{~nm}$. At the time, no image has been obtained on higher stages of the impactor to verify if bigger MWCNT are present or not in effluents. Indeed, for the reason explained before: the topography is too important and overpasses the $z$ scanning range of the AFM. A solution to image a higher stage would be to observe the deposits in SEM. This first hypothesis seems to be confirmed by the observations made on STEM images (Figure 5) of the two compounds: The initial distributions of MWCNT in the compounds are different for the two matrices (PA-6 or PMMA). MWCNT are better dispersed in PA-6 than in PMMA where MWCNT form some agglomerates of 200 to $500 \mathrm{~nm}$. Maybe these agglomerates are not split during the extrusion. This observation could also explain the modification of the thermal degradation with the agglomerated MWCNT in PMMA, where scissions of PMMA and carbon nanotubes agglomerates are more difficult than in PA-6, where nanotubes are initially better dispersed. Finally, another hypothesis to explain the absence of MWCNT on the first stage of the impactor could be the influence of the matrix (chemical structure) on the thermal degradation of the compound (matrices + MWCNT) during the combustion. However, no experimental result can confirm this hypothesis.

At the moment, AFM observations are only qualitative, but the further steps will be to use AFM image and dedicated software analysis (grain analysis for example) to extract more quantitative results as for example the particle size, the volume and surface distribution, the surface concentration, the 3D fractal dimension of the aggregates, and so on. In addition, AFM observations will be coupled with SEM observations and EDX local chemical analysis, to try to explain the observed physicochemical modifications.

\section{CONCLUSION}

Investigations on fire behaviour and structure of aerosols issued from PMMA/MWCNT and PA-6/MWCNT nanocomposites have been carried out. Fire behaviour is clearly influenced by the presence of carbon nanotubes. The association of cone calorimeter and PCFC allows detailed information about the mechanisms of nanocomposite degradation. Because of the low quantity of material tested, PCFC technique does not allow to highlight physical mechanisms based on protective layer formation or modification in heat transfer. Characterizations of aerosols and soot issued from combustion of the studied nanocomposites have been performed using a low-pressure cascade impactor coupled with cone calorimeter. Presence of carbon nanotubes in effluents during combustion was particularly investigated. The main information issued from the experiments showed the following:

- There is an important modification in fire behaviour of the materials because of the addition of MWCNT (significant decrease of peak of heat release rate). This effect depends on the matrix and appears at different mass ratios of carbon nanotubes.

- There is no significant difference in mass size distribution of aerosols between PA-6 and the corresponding PA-6/MWCNT nanocomposites.

- The incorporation of MWCNT into PMMA seems to reduce the proportion of larger particles emitted, in the range from 0.6 to $2.5 \mu \mathrm{m}$. Conversely, the particle size distribution for the PMMA with MWCNT shows an increase in larger particles (larger than $4 \mu \mathrm{m}$, corresponding to the last three size classes of the impactor), compared with PMMA alone.

- Carbon nanotubes have been observed by AFM for a cut-off diameter of $30 \mathrm{~nm}$ only for PA-6/ MWCNT nanocomposite.

In spite of these results, extracting unambiguous conclusion remains challenging. Test protocol could be improved to extract some information from soot coming from higher stage of the impactor. Besides, work is currently in progress to extract quantitative results about particle size from AFM images to conclude on the aspect ratio of the soot. Moreover, a high-resolution SEM coupled with a 
local chemical analysis by EDX could be useful to underline our findings. Finally, more developments are necessary to decide between the different hypotheses, in order to have an insight of the different chemical mechanisms taking place between the matrix and the nanoparticle during thermal degradation.

\section{ACKNOWLEDGEMENTS}

The authors acknowledge the financial support given by the French National Research Agency (ANR). The authors would like to thank Digital Surf SARL for making Digital Surf's MountainsMap licences available in the framework of the Digital Surf's Mount Shasta technical cooperation programme. All the NANOFEU partners (Institut National de l'Environnement et des Risques and PlasticsEurope) are also gratefully acknowledged for their collaboration. All authors would like to especially acknowledge the late Mr Gensous for his contribution in this project.

\section{REFERENCES}

1. Hu Y.H., Chen C.Y., Wang C.C. Viscoelastic properties and thermal degradation kinetics of silica/PMMA nanocomposites, Polymer Degradation and Stability 2004; 84:545-553.

2. Gilman JW. Flammability and thermal stability studies of polymer layered-silicate clay/nanocomposites. Applied Clay Science 1999; 15:31-49.

3. Jash P, Wilkie CA. Effects of surfactants on the thermal and fire properties of poly(methyl methacrylate)/clay nanocomposites. Polymer Degradation and Stability 2005; 88:401-406.

4. Friederich B, Laachachi A, Ferriol M, Ruch D, Cochez M, Toniazzo V. Tentative links between thermal diffusivity and fire-retardant properties in poly(methyl methacrylate)-metal oxide nanocomposites. Polymer Degradation and Stability 2005; 95:1183-1193.

5. Zhu J, Start P, Mauritz K.A., Wilkie C.A. Thermal stability and flame retardancy of poly(methyl methacrylate)-clay nanocomposites. Polymer Degradation and Stability 2002; 77:253-258.

6. Xu Y., Brittain W.J., Xue C., Eby RK. Effect of clay type on morphology and thermal stability of PMMA-clay nanocomposites prepared by heterocoagulation method. Polymer 2004; 45:3735-3746.

7. Sahoo P.K., Samal R. Fire retardancy and biodegradability of poly(methyl methacrylate)/montmorillonite nanocomposite. Polymer Degradation and Stability 2007; 92:1700-1707.

8. Marinovic-Cincovic M., Popovic M.C., Novakovic M.M., Nedeljkovic J.M.. The influence of $\beta$-FeOOH nanorods on the thermal stability of poly(methyl methacrylate). Polymer Degradation and Stability 2007; 92:70-74.

9. Maynard A.D. Nanotechnology: assessing the risks. Nanotoday 2006; 2:22-32.

10. NANOMMUNE Project 2008-2011 - 7th EU Framework Program (ki.projectcoordinator.net/projectweb/ 490599f501 abc/Index.html, accessed May 2012).

11. NANOSAFE. Safe production and use of nanomaterials (www.nanosafe.org, accessed May 2012).

12. Nyden M.R., Harris R.H., Kim Y.S., Davis R.D., Marsh N.D., Zammarano M. Characterizing particle emissions from burning polymer nanocomposites. NIST-Nanotech 2009; ISBN 978-1-4398-3401-5 Vol. 1, 2010.

13. Nyden M.R, Zammarano M, Harris R.H, Krammer R, Uddin N.M, Marsh N.D. Characterizing particle emissions from burning polymer nanocomposites. Proceedings of INTERFLAM 2010 Conference, Nottingham, UK, 2010; 623-628.

14. Chivas-Joly C., Guillaume E., Ducourtieux S., Saragoza L., Lesenechal D., Lopez-Cuesta J.M., Longuet C., Duplantier S., Sonnier R., Bertrand J.P., Calogine D., Minisini B., Parisse D. Influence of carbon nanotubes on fire behavior and on decomposition products of thermoplastic polymers. Proceedings of INTERFLAM 2010 Conference, Nottingham, UK, 2010; 1375-1386.

15. NANOFEU Project - Agence Nationale de la Recherche (France) (http://www.ineris.fr/nanofeu, accessed May 2012).

16. Chivas C, Guillaume E, Saragoza L, Ducourtieux S, Sainrat A, Macé T. Characterization of nanoparticles in fire effluents. Poster, International Conference on Modification, Degradation and Stability of Polymers (MoDeSt), Liège, Belgium, 2008; 7-11.

17. Calogine D, Duplantier S, Chivas C, Guillaume E, Lopez-Cuesta J-M, Longuet C, Minisini B, Gensous F, Chesné L. The NANOFEU project: objectives and tools. International Conference on Safe Production and Use of Nanomaterials - NANOSAFE 2008, Grenoble, France, 2008.

18. Hirata T, Kashiwagi T., Brown J. E. Thermal and oxidative degradation of poly(methyl methacrylate): weight loss. Macromolecules $1985 ; \mathbf{1 8}: 1410-1418$.

19. Kashiwagi T., Inaba A., Brown J. E., Hatada K., Kitayama T., Masuda E. Effects of weak linkages on the thermal and oxidative degradation of poly(methyl methacrylates). Macromolecules 1986; 19:2160-2168.

20. Holland B. J., Hay J. N. The kinetics and mechanisms of the thermal degradation of poly(methyl methacrylate) studied by thermal analysis - Fourier transform infrared spectroscopy. Polymer 2001; 42:4825-4835.

21. Inaba A., Kashiwagi T., Brown EJ. Effects of initial molecular weight on thermal degradation of poly(methyl methacrylate) part 1 model 1. Polymer Degradation and Stability 1988; 21:1-20.

22. Kashiwagi T., A Inaba. Behavior of primary radicals during thermal degradation of poly(methyl methacrylate). Polymer Degradation and Stability 1989; 26:161-184.

23. Manring L. Thermal degradation of poly(methyl methacrylate), 4. Random side-group scission. Macromolecules 1991; 24:3304-3309. 
24. McNeil C. A study of the thermal degradation of methyl methacrylate polymers and copolymers by thermal volatilization analysis. European Polymer Journal 1968; 4:21-30.

25. Brown E, Kashiwagi T. Gas phase oxygen effect on chain scission and monomer content in bulk poly(methyl methacrylate) degraded by external thermal radiation. Polymer Degradation and Stability 1996; 52:1-10.

26. Bolland J.L. Kinetic studies in the chemistry of rubber and related materials. I. The thermal oxidation of ethyl linoleate. Proceedings of the Royal Society of London. Series A: Mathematical and Physical Sciences, 1946; 186:218-236.

27. Bolland J.L., Gee G. Kinetic studies in the chemistry of rubber and related materials. III. Thermochemistry and mechanisms of olefin oxidation. Transactions of the Faraday Society 1946; 42:244-252.

28. Bolland J.L., Gee G. Kinetic studies in the chemistry of rubber and related materials. II. The kinetics of oxidation of unconjugated olefins. Transactions of the Faraday Society 1946; 42:236-243.

29. Kashiwagi T., Du F., Winey K. I., Groth K. M., Shields J. R., Bellayer S. P., Kim H., Douglas J. F. Flammability properties of polymer nanocomposites with single-walled carbon nanotubes: effects of nanotube dispersion and concentration. Polymer 2005; 46:471-481.

30. Kashiwagi T., Fagan J., Douglas J. F., Yamamoto K., Heckert A. N., Leigh S. D., Obrzut J., Du F., Lin-Gibson S., Mu M., Wine K. I., Haggenmueller R. Relationship between dispersion metric and properties of PMMA/SWNT nanocomposites. Polymer 2007; 48:4855-4866.

31. Kashiwagi T., Mu M., Winey K., Cipriano B., Raghavan S.R., Pack S., Rafailovich M., Yang Y., Grulke E., Shields J., Harris R., Douglas J. Relation between the viscoelastic and flammability properties of polymer nanocomposites. Polymer 2008; 49:4358-4368.

32. Levchik S. V., Weil E. D., Lewin M. Review - thermal decomposition of aliphatic nylons. Polymer International 1999; 48:532-557.

33. Strauss S., Wall L. A. Pyrolysis of polyamides. Journal of Research of the National Bureau of Standards 1958; 60:39-45.

34. Kamerbeek B, Kroes G.H, Grolle W. Thermal Degradation of Some Polyamides. Soc. Chem. Ind. Monograph No. 13, Society of Chemical Industry, London, 1961.

35. Dussel H.J., Rosen H., Hummel D.O. Feldionen- und Elektronenstoß-Massenspektrometrie von Polymeren und Copolymeren, 5. Aliphatische und aromatische Polyamide und Polyimide. Die Makromolekulare Chemie 1976; 177:2343-2368.

36. Ohtani H., Nagaya I., Sugimura Y., Tsuge S. Studies on thermal degradation of aliphatic polyamides by pyrolysis glass capillary chromatography. Journal of Analytical and Applied Pyrolysis 1982; 4:117-131.

37. Michal J., Mitera J., Kubat J. Major pyrolysis and thermoxidative products from certain polyamides. Fire and Materials 1981; 5:1-5.

38. Schartel B., Potschke P., Knoll U., Abdel-Goad M. Fire behaviour of polyamide 6/multiwall carbon nanotube Nanocomposites. European Polymer Journal 2005; 41:1061-1070.

39. Lanska B., Doskocilova D., Matisova-Rychla L., Puffr R., Rychly J. Thermo-oxidation of lactam-based polyamides with amino end-groups. Thermo-oxidation of hexano-6-lactam and decomposition of 6-hydroperoxy hexano-6-lactam in the presence of primary amines. Polymer Degradation and Stability 1999; 63:469-479.

40. ISO 5660-1:2002: Reaction to fire tests - heat release, smoke production and mass loss rate - part 1: heat release rate (cone calorimeter method)

41. Baron P, Willeke K. Aerosol Measurement - Principles, Techniques, and Applications. Wiley Interscience: New York, 2001.

42. ASTM D7309-11 Standard Test Method for Determining Flammability Characteristics of Plastics and Other Solid Materials Using Microscale Combustion Calorimetry.

43. Lyon R., Walters R. Pyrolysis combustion flow calorimetry. Journal of Analytical ad Applied Pyrolysis 2004; 71:27-46.

44. ISO DIS 29904: Fire chemistry - generation and measurement of aerosols (Standard under development by ISO TC92/SC3).

45. Tewarson A. Generation of heat and chemical compounds in fires. In The SFPE Handbook of Fire Protection Engineering ( $3^{\text {rd }}$ edition), Chapter 4, Section 3, pp. 3-82 to 3-161. The National Fire Protection Association Press: Quincy, MA, USA, 2002.

46. Tewarson A. Flammability. In Physical Properties of Polymers Handbook, Chapter 42, Mark J.E. (ed). American Institute of Physics: Woodbury, NY, USA, 1996; 577-604

47. Luche J., Rogaume T., Richard F., Guillaume E. Characterization of thermal properties and analysis of combustion behaviour of PMMA in a cone calorimeter. Fire Safety Journal 2011; 46:451-461. 